\title{
Mechanical Design of Long-Term Body-Adhered Medical Devices to Maximize On-Body Survival
}

\author{
Brian Ferry, John Abraham
}

University of St. Thomas, St. Paul, MN, USA

Correspondence to: Brian Ferry, brian.ferry@stthomas.edu; John Abraham, jpabraham@stthomas.edu Keywords: Finite Element Analysis, Explicit Dynamics, Numerical Simulation, Comparative Analysis, Medical Device, Body-Worn Device, Mechanical Design

Received: September 17, $2021 \quad$ Accepted: September 27, $2021 \quad$ Published: September 30, 2021

Copyright $\odot 2021$ by author(s) and Scientific Research Publishing Inc.

This work is licensed under the Creative Commons Attribution International License (CC BY 4.0).

http://creativecommons.org/licenses/by/4.0/

\section{(c) (1) Open Access}

\section{ABSTRACT}

Long-term, body-adhered medical devices rely on an adhesive interface to maintain contact with the patient. The greatest threat to on-body adhesion is mechanical stress imparted on the medical device. Several factors contribute to the ability of the device to withstand such stresses, such as the mechanical design, shape, and size of the device. This analysis investigates the impact that design changes to the device have on the stress and strain experienced by the system when acted on by a stressor. The analysis also identifies the design changes that are most effective at reducing the stress and strain. An explicit dynamic finite element analysis method was used to simulate several design iterations and a regression analysis was performed to quantify the relationship between design and resultant stress and strain. The shape, height, size, and taper of the medical device were modified, and the results indicate that, to reduce stress and strain in the system, the device should resemble a square in shape, be short in height, and small in size with a large taper. The square shape experienced $17.5 \%$ less stress compared to the next best performing shape. A $10 \%$ reduction in device height resulted in a $21 \%$ reduction in stress and $24 \%$ reduction in strain. A $20 \%$ reduction in device size caused a $7 \%$ reduction in stress and $2 \%$ reduction in strain. A $20 \%$ increase in device taper size led to a negligible reduction in stress and a $6 \%$ reduction in strain. The height of the device had the greatest impact on the resultant stress and strain.

\section{INTRODUCTION}

Long-term, body-adhered medical devices are products that are either not implanted or only partially implanted within a patient and adhered to the skin for a period of longer than 24 hours [1]. They can perform diagnostic or therapeutic tasks, such as biometric sensing and drug infusion. Examples of such de- 
vices include wearable electrocardiogram (ECG) devices [2], drug infusion pumps [3], continuous glucose monitoring (CGM) devices [4], and patch-style insulin delivery systems [5]. These devices rely on an adhesive patch or adhesive substrate to maintain attachment to the patient's body (Figure 1). Additionally, they are designed to be worn by patients unobtrusively, leaving them free to participate in most daily activities.

For devices that are not implanted, loss of adhesion can be addressed by reattaching the device or by placing a new adhesive patch on the device. There may be momentary loss of data or therapy, but the device remains functional. Partially-implanted devices are not able to be redeployed. Loss of adhesion means complete loss of data or therapy until a new device can be installed.

These devices are often expensive, and for the device to become dislodged from the body while it is still functional leads to a direct cost increase to the patient, in addition to the anxiety induced by loss of data or therapy [7]. A reliable method of adhesion can ease anxiety and reduce mental burden so that the patient can return to their daily life. Thus, the design of the adhesion method becomes a critical effort for increasing the reliability of the overall system and maximizing patient satisfaction.

Use of high strength adhesive materials can extend the duration of wear. However, adhesion strength cannot be so high that it causes tissue trauma upon device removal [8]. This upper limit to the material strength leaves the adhesive vulnerable to chemical, biological, and mechanical stresses [9]. Since the adhesive material cannot be solely relied upon to increase reliability, other factors must be explored and optimized to ensure that the medical device remains on-body.

The mechanical design of the medical device is one such factor that can be optimized to increase on-body survival. More specifically, the design of the device can improve the system's ability to withstand mechanical stresses. These stresses can come from clothing, sporting equipment, collisions with solid objects, etc. Changing the design of the device can affect its ability to deflect these stresses.

This investigation will change different aspects of the mechanical design of a sample medical device to understand how to optimize the design for on-body survival. The investigation uses an explicit dynamic finite element analysis (ANSYS v. 2020) to quantify the mechanical shear stress and shear strain experienced by a medical device system under defined conditions in a time-varying environment.

\section{NUMERICAL MODEL}

\subsection{Model Geometry}

The model includes a medical device, tissue substrate, and stressor object as shown in Figure 2. The

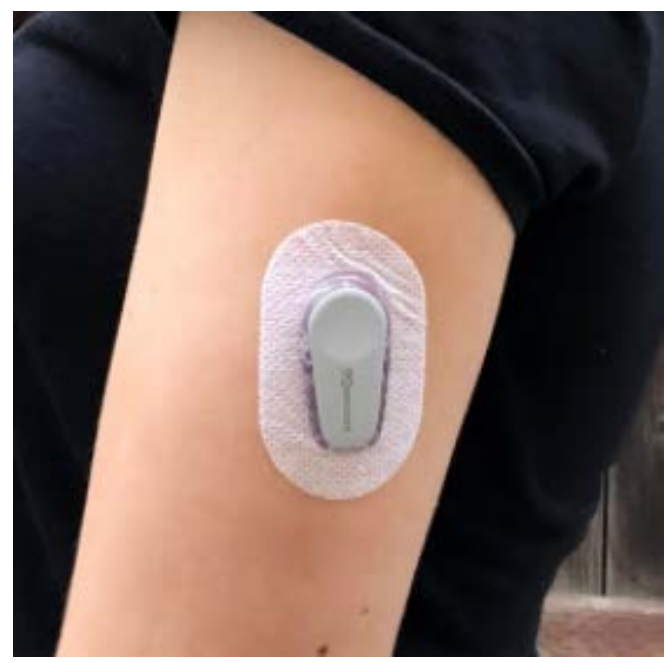

Figure 1. CGM device and related adhesive patch assembly (Dexcom G6) [6]. Photo by: Ashley Neuhaus @typelovely. 


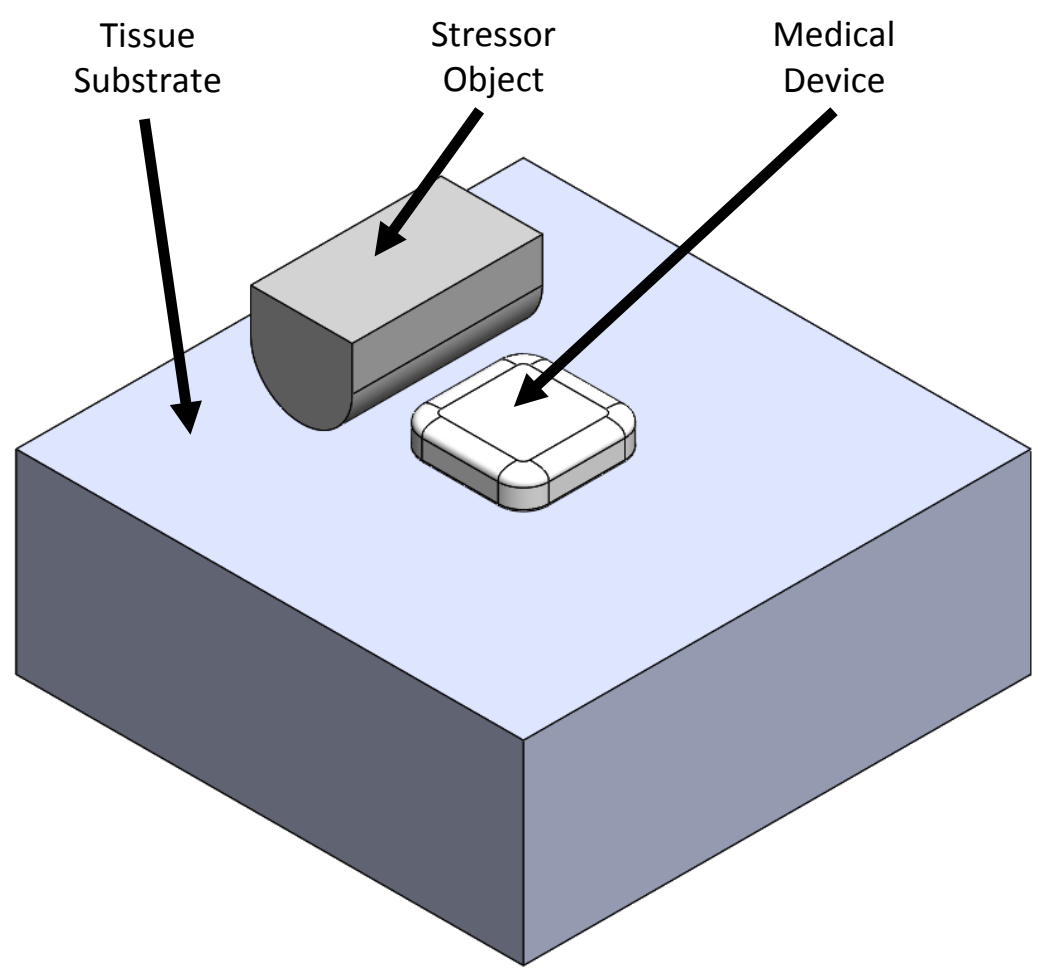

Figure 2. Model geometry.

bottom of the medical device is assumed to be adhered to the tissue substrate at the adhesion interface. During the simulation, the stressor object translates toward and collides with the medical device. The resulting mechanical shear stress and shear strain experienced will be calculated. Several simulations will be performed, each representing a design change to the shape or size of the medical device. The geometry of the tissue substrate and stressor object will not change. The maximum stress and strain across all designs will then be compared and results analyzed.

The skin and subcutaneous thickness is $39.9 \mathrm{~mm}$ (1.547 in), which represents the upper limit of adipose tissue thickness at the anterior abdomen in a study population of 449 adult males [10]. For this simulation, the stressor object is a rounded, rigid object that collides with the medical device tangentially to the surface plane of the skin. The simulation represents a patient who walks too closely to a solid object, such as a door frame, and contacts it with the device.

\subsection{Material Properties}

The material properties of all objects will remain constant throughout the study. The material selection and related mechanical properties for each object are shown in Table 1.

The medical device is assumed to be fabricated from a thermoplastic; polyethylene is an appropriate representative material. The mechanical properties of human tissue are derived from experimental data [11-14]. Tissue composition varies widely between patients. In order to bound the calculations, the minimum Young's Modulus in the experimental range will be used. Structural steel was chosen for the stressor object to ensure that it behaves like a rigid object, although the results are insensitive to this material choice.

\subsection{Use of Symmetry}

This model will use symmetry to reduce simulation time. Each simulated design iteration maintained symmetry across the XY plane, shown in blue in Figure 3. 
Table 1. Material selection and properties.

\begin{tabular}{ccccc}
\hline Component & Material & Young's Modulus & Poisson's Ratio & Density \\
\hline Device & Polyethylene & $1.10 \mathrm{e}^{9} \mathrm{~Pa}$ & 0.42 & $950 \mathrm{~kg} / \mathrm{m}^{3}$ \\
Skin Substrate & Human Tissue & $0.42 \mathrm{e}^{6} \mathrm{~Pa}(\mathrm{Min})[11]$ & $0.48[12]$ & $900 \mathrm{~kg} / \mathrm{m}^{3}[13]$ \\
& & $0.85 \mathrm{e}^{6} \mathrm{~Pa}(\mathrm{Max})[11]$ & & \\
Stressor Object & Structural Steel & $2.00 \mathrm{e}^{11} \mathrm{~Pa}$ & 0.30 & $7850 \mathrm{~kg} / \mathrm{m}^{3}$ \\
\hline
\end{tabular}

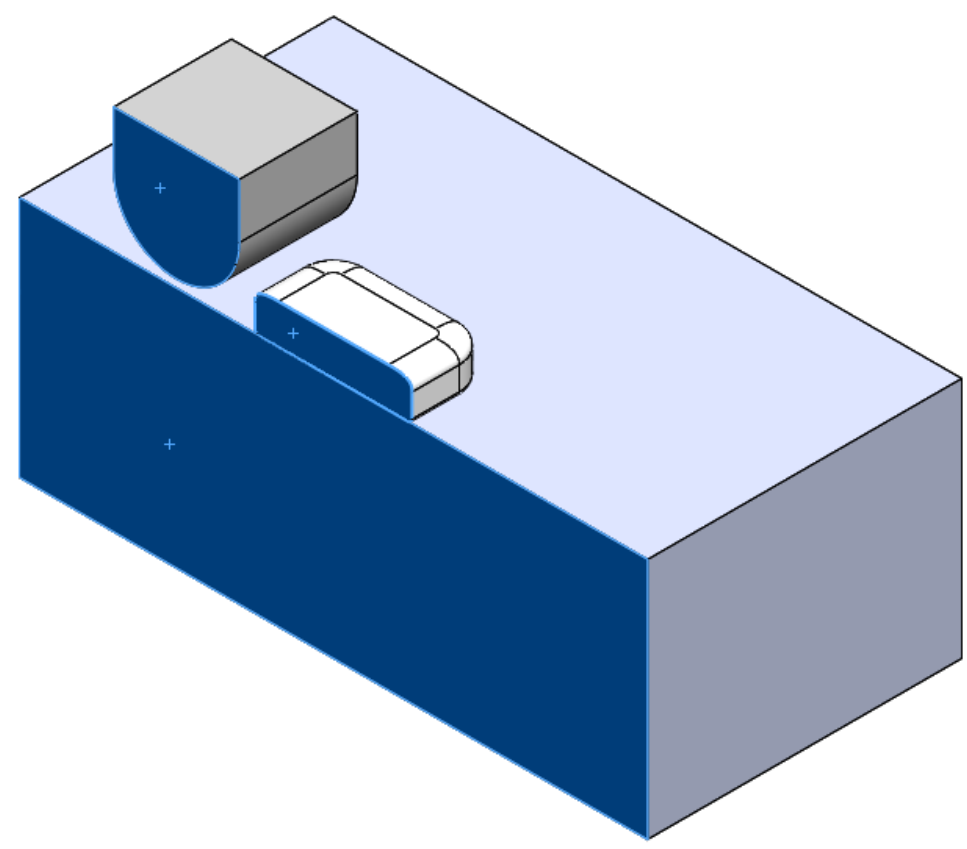

Figure 3. Symmetry plane.

\subsection{The Computational Mesh}

The placement of elements and nodes within a model affects the accuracy of the calculations. Additionally, increasing the number of elements within the model correspondingly increases the simulation time. Therefore, an efficient model concentrates element and node placement at the locations of highest interest [15]. In this model, the locations of highest interest are where the maximum stress and strain occur, which is also at the adhesion interface. The resulting mesh is shown in Figure 4.

\subsection{Analysis Settings}

During the simulation, the stressor object will translate toward and collide with the medical device tangential to the skin surface (Figure 5). This interaction resembles the standardized test methods for shear adhesion according to ASTM D3654 [16]. Expanding on the earlier example of a patient colliding with a solid object such as a door frame, the velocity of the stressor will be 1.43 meters per second - the average adult male walking speed [17]. At that velocity, a simulation end time of 0.0175 seconds will translate the stressor to the midway point of the device. The bottom of the tissue substrate is fixed in place by its connection with deeper-layer tissue. On all free surfaces, a zero-stress condition is applied. At the symmetry plane, the normal gradient of all variables is zero.

The time steps used to integrate the unsteady simulation were $\sim 8 \mathrm{e}-4$ seconds. The potential sensitivity of the results to the value of the time steps will be discussed later. 


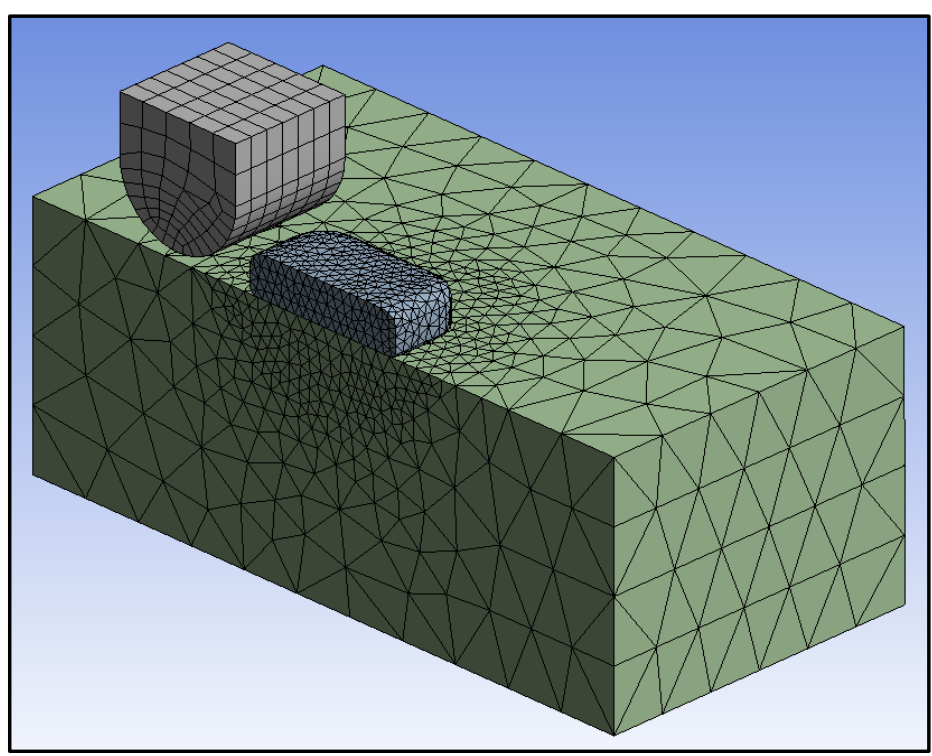

Figure 4. The computational mesh.

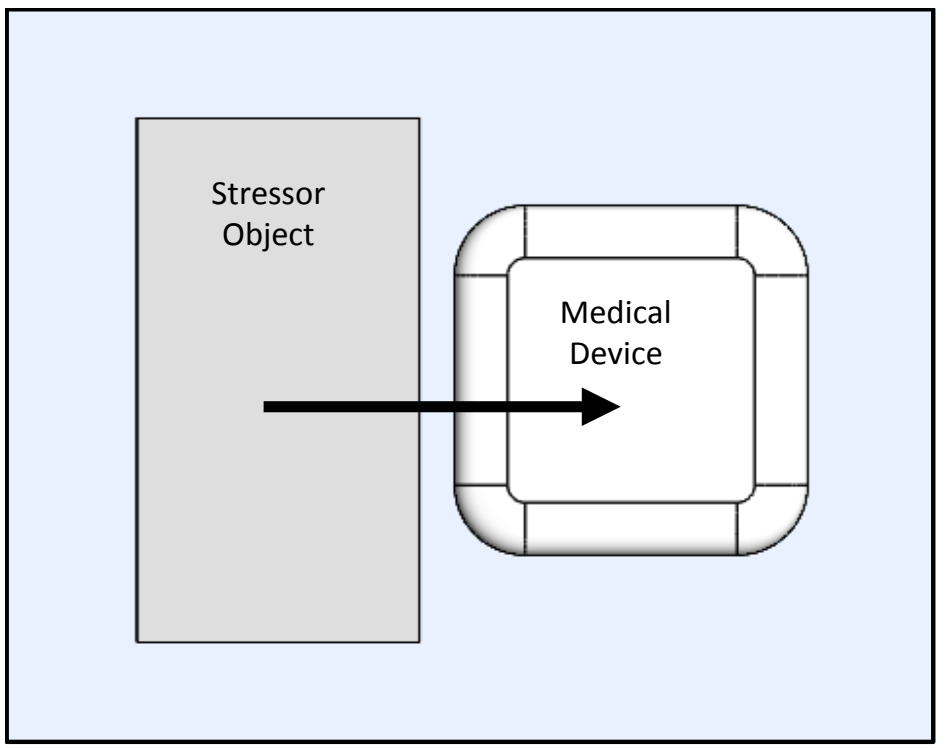

Figure 5. Stressor object translation.

\section{RESULTS AND DISCUSSION}

\subsection{Maximum Elastic Strain}

The maximum shear elastic strain and the maximum shear stress are the target metrics for each simulation. The maximum strain consistently occurs within the tissue substrate directly below the medical device (after the stressor has impacted the medical device and moved halfway across the device). The time at which this maximum occurs varies slightly across simulations, but a representative result is shown in Figure 6. In the figure, the stressor is moved over the device and it has clearly pressed the medical device downwards into the resilient tissue. It is noteworthy that the shear strain is not completely symmetric, because of the direction of motion of the stressor. The colors are keyed to the color legend on the left-hand side of the image. The largest strain is adjacent to the leading and trailing edges of the adhesion interface and therefore is relevant to the issue of whether the device would maintain its on-body adhesion. 


\begin{tabular}{|l|l|}
0.56933 & Max \\
0.50607 \\
0.44281 \\
0.37955 \\
0.31629 \\
0.25303 \\
0.18978 \\
0.12652 \\
0.063258 \\
0 Min
\end{tabular}

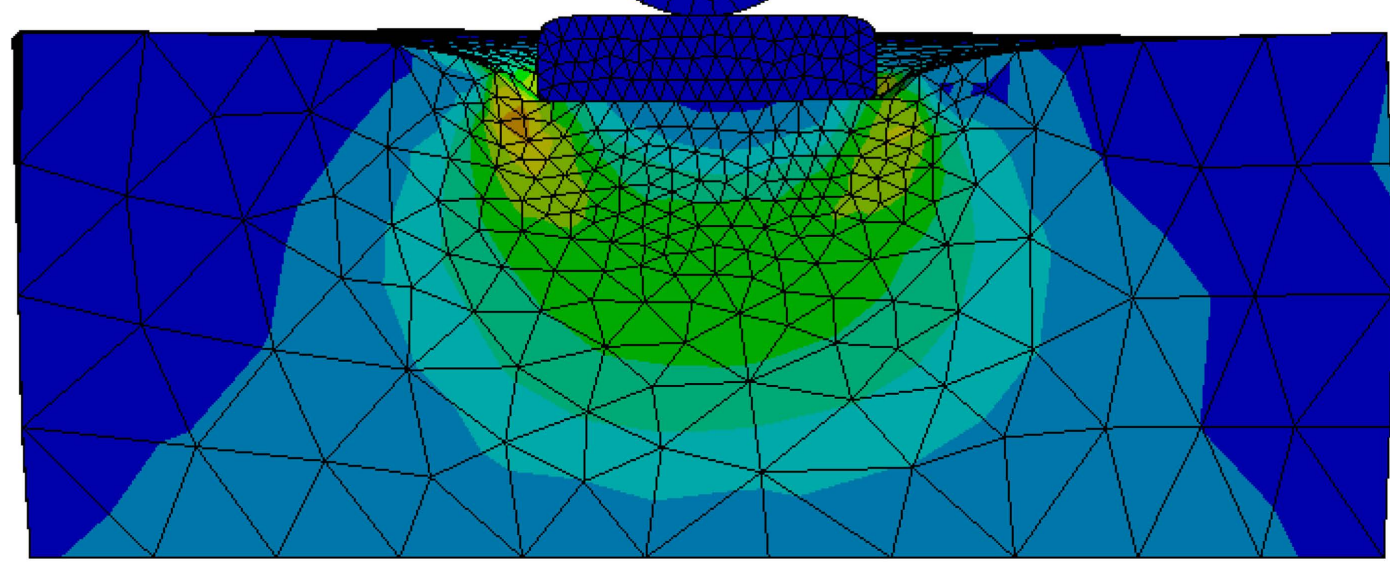

Figure 6. Representative maximum elastic strain results.

\subsection{Maximum Stress}

The maximum stress consistently occurs within the medical device adjacent to the adhesion interface. The time at which this maximum occurs varies across simulations, but a representative result is shown in Figure 7. As evident from the image, the stress is low in the tissue, partly because of the deformable character of the tissue. The units of stress in Figure $7 \mathrm{are} \mathrm{Pa}$, as indicated by the color legend. As with strain, the largest values of stress are at the adhesion interface and thus are directly relevant to the maintenance of the medical device.

\subsection{The Influence of Various Parameters on the Stress and Strain Results}

This simulation was performed to elucidate how changes to the mechanical design of the medical device will impact the stress and strain imparted by the stressor object. There are four design characteristics that will be investigated: 1) shape, 2) height, 3) size, and 4) taper. The set of simulations within a design characteristic category is called a "suite". The simulation suites will be performed in the order previously listed (i.e., shape first, height second, etc.). Upon completion of each suite, the optimal design will be identified through direct comparison or by linear regression analysis. In suites that use linear regression, a coefficient of determination above 0.9 will be considered significantly meaningful [18].

\subsubsection{Device Shape}

The first suite of simulations will focus on the shape of the medical device. In these simulations, the factors that will be held constant include the height, footprint area, edge taper, and corner fillet dimensioning. The naming convention for these models is best illustrated by Figure 5, which shows a top view of the "Square Flat" model. During the simulation, the stressor object translates to the right, contacting a flat face of the model; hence, the name "Square Flat". For the Square, it is unknown how the orientation of the device will affect the final calculations, so multiple orientations will be studied. The shapes selected and resulting calculations are shown in Table 2.

The lowest overall stress and strain were both recorded by the Square configuration. In particular, the Square significantly outperformed all other shapes in minimizing shear stress-17.5\% less than the Triangle, $21.4 \%$ less than the Circle, and $37.8 \%$ less than the Rectangle. 
Table 2. Device shape-design iterations and calculated results.

\begin{tabular}{|c|c|c|c|}
\hline Model & Image & $\begin{array}{c}\text { Max Shear Strain } \\
(\mathrm{mm} / \mathrm{mm})\end{array}$ & Max Shear Stress $(\mathrm{Pa})$ \\
\hline Circle & & 0.76287 & $2,804,600$ \\
\hline $\begin{array}{l}\text { Square } \\
\text { Flat }\end{array}$ & & 0.71584 & $2,204,200$ \\
\hline $\begin{array}{l}\text { Square } \\
\text { Corner }\end{array}$ & & 0.78384 & $1,972,100$ \\
\hline $\begin{array}{l}\text { Rectangle } \\
\text { Long }\end{array}$ & & 0.74315 & $3,543,200$ \\
\hline $\begin{array}{c}\text { Rectangle } \\
\text { Short }\end{array}$ & & 0.74114 & $2,733,300$ \\
\hline $\begin{array}{c}\text { Triangle } \\
\text { Flat }\end{array}$ & & 0.75586 & $2,540,300$ \\
\hline $\begin{array}{l}\text { Triangle } \\
\text { Corner }\end{array}$ & & 1.02790 & $2,670,700$ \\
\hline
\end{tabular}

\subsubsection{Device Height}

The second suite of simulations focuses on the height of the device. The height of the baseline model is $6.350 \mathrm{~mm}$. Three additional designs will be tested, each of which increases or decreases the height of the baseline model in 10\% increments. The calculated results are shown in Table 3 and a linear regression analysis of the data is depicted in Figure 8. 


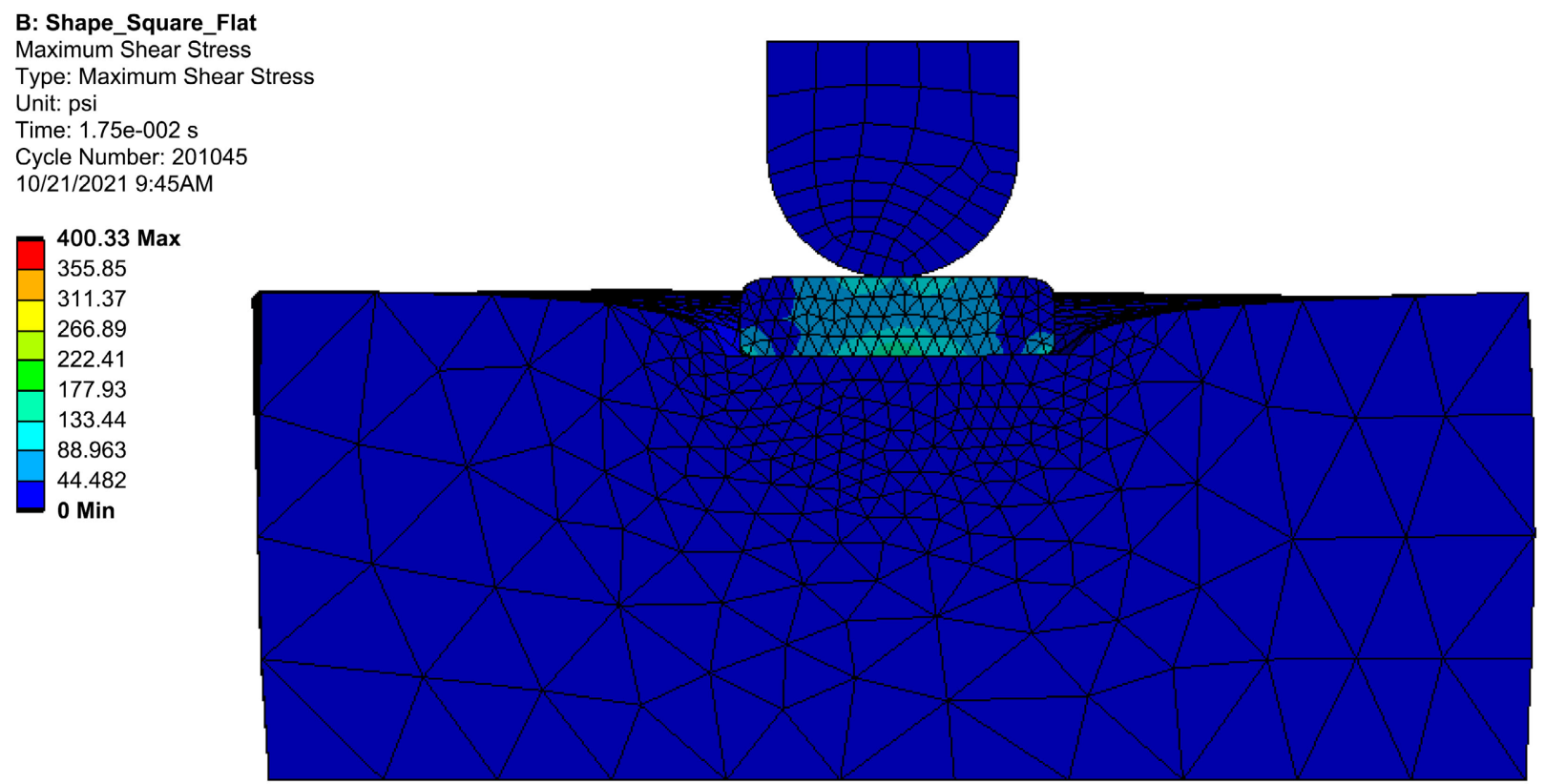

Figure 7. Representative maximum stress results.

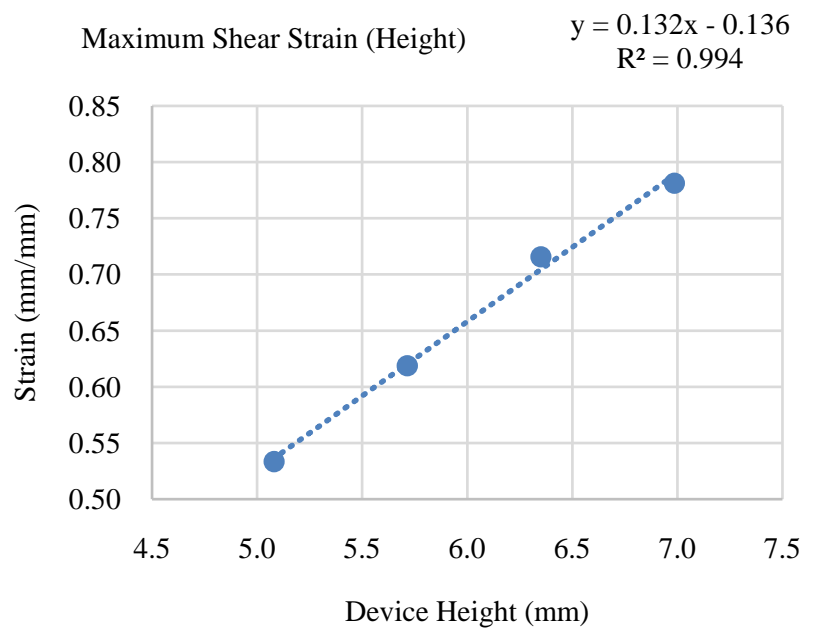

(a)

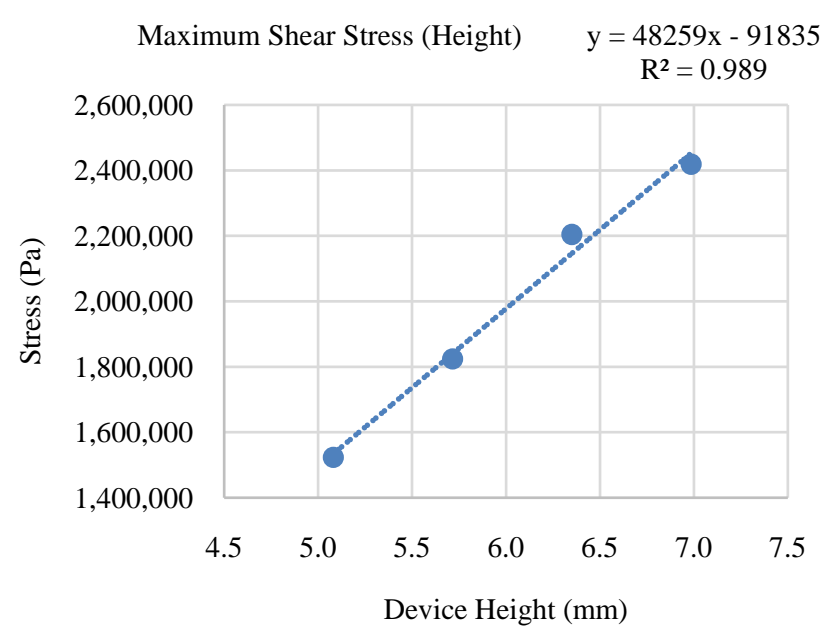

(b)

Figure 8. Device height-regression analysis. (a) Maximum shear strain; (b) Maximum shear stress.

The regression analysis reveals a clear trend that a shorter device height leads to lower stress and strain. Shortening the device by $1 \mathrm{~mm}$ will decrease the strain by $0.13 \mathrm{~mm} / \mathrm{mm}$ and the stress by $4.8 \mathrm{e}^{5} \mathrm{~Pa}$. The coefficient of determination for these transfer functions far exceeds the requirement of 0.9 and therefore is considered to be significantly meaningful.

\subsubsection{Device Size}

The third suite of simulations will focus on the size of the device-that is, the footprint of the device when viewed from the top. The design will be changed by lengthening or shortening the sides of the device in $20 \%$ increments. The side length of the baseline device is $25.4 \mathrm{~mm}$ and three additional designs were tested. The resulting design iterations are detailed in Table 4 . The calculated results are shown in Table 4 and a linear regression analysis of the data is provided in Figure 9.

The regression analysis shows a slight positive association between the size of the device and the 
Table 3. Device height-design iterations and calculated results.

\begin{tabular}{|c|c|c|c|c|}
\hline Model & $\begin{array}{l}\text { Height } \\
(\mathrm{mm})\end{array}$ & Image & $\begin{array}{l}\text { Max Shear Strain } \\
(\mathrm{mm} / \mathrm{mm})\end{array}$ & $\begin{array}{c}\text { Max Shear Stress } \\
(\mathrm{Pa})\end{array}$ \\
\hline Tall & 6.985 & & 0.78135 & $2,418,900$ \\
\hline Baseline & 6.350 & & 0.71584 & $2,204,200$ \\
\hline Short & 5.715 & & 0.61889 & $1,824,700$ \\
\hline Thin & 5.080 & & 0.53329 & $1,523,900$ \\
\hline
\end{tabular}

Table 4. Device size-design iterations and calculated results.

\begin{tabular}{lccc}
\hline Model & $\begin{array}{c}\text { Side Length } \\
(\mathrm{mm})\end{array}$ & $\begin{array}{c}\text { Max Shear Strain } \\
(\mathrm{mm} / \mathrm{mm})\end{array}$ & $\begin{array}{c}\text { Max Shear Stress } \\
(\mathrm{Pa})\end{array}$ \\
Enlarged & 30.48 & 0.37076 & $2,149,200$ \\
Baseline & 25.40 & & \\
\hline
\end{tabular}


ensuing stress and strain. Therefore, a smaller device tends to correspond to lower values of both strain and stress. However, the coefficients of determination for the stress $\left(R^{2}=0.4079\right)$ and strain $\left(R^{2}=0.6088\right)$ analyses do not provide enough confidence to justify significant design changes.

\subsubsection{Device Taper}

The final suite of simulations will focus on the taper of the top edge of the device. As seen from the images, the devices have rounded edges which may influence the stress imparted to the medical device and tissue. The dimensions are described by the horizontal extent of the rounding-known as the "run"-and the vertical extent-known as the "rise". The baseline model has a rise of $1.905 \mathrm{~mm}$ and a run of 3.810 $\mathrm{mm}$. Three other iterations used different values of both the rise and run. The details of all designs and the results are listed in Table 5. A linear regression of the data is shown in Figure 10.

The regression analysis illustrates that the taper of the device has negligible impact on the strain experienced by the system. Additionally, a coefficient of determination of 0.0965 does not indicate that the correlation is meaningful. The stress analysis, however, does indicate a strong negative relationship between

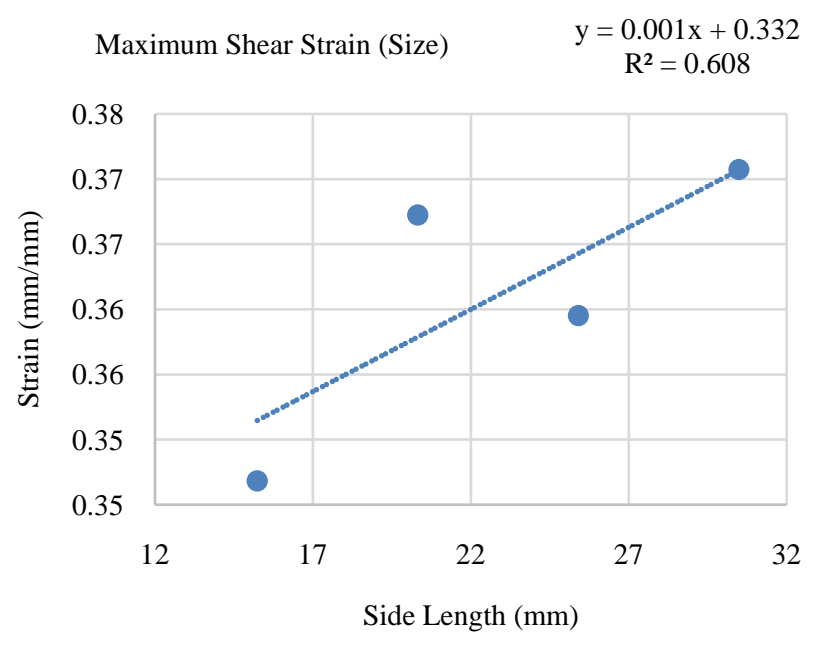

(a)

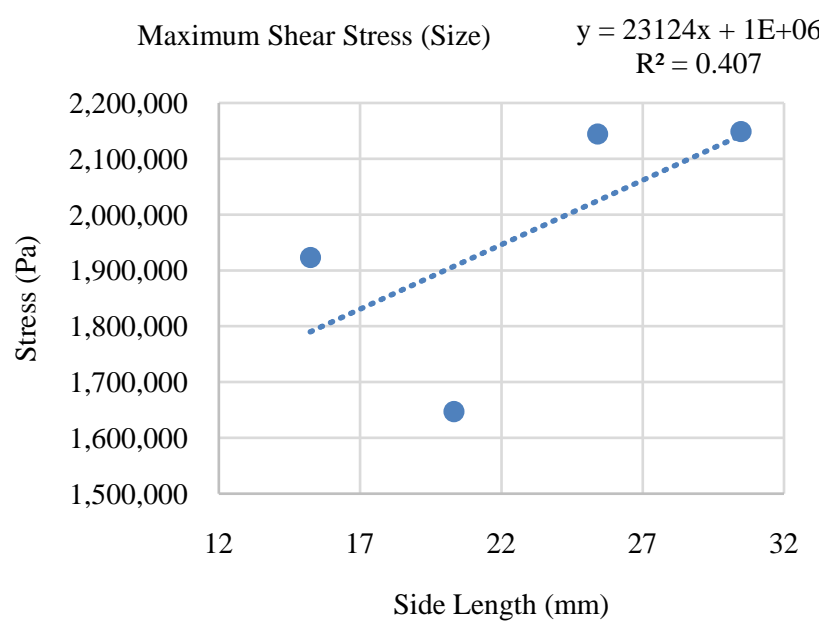

(b)

Figure 9. Device size-regression analysis. (a) Maximum shear strain; (b) Maximum shear stress.

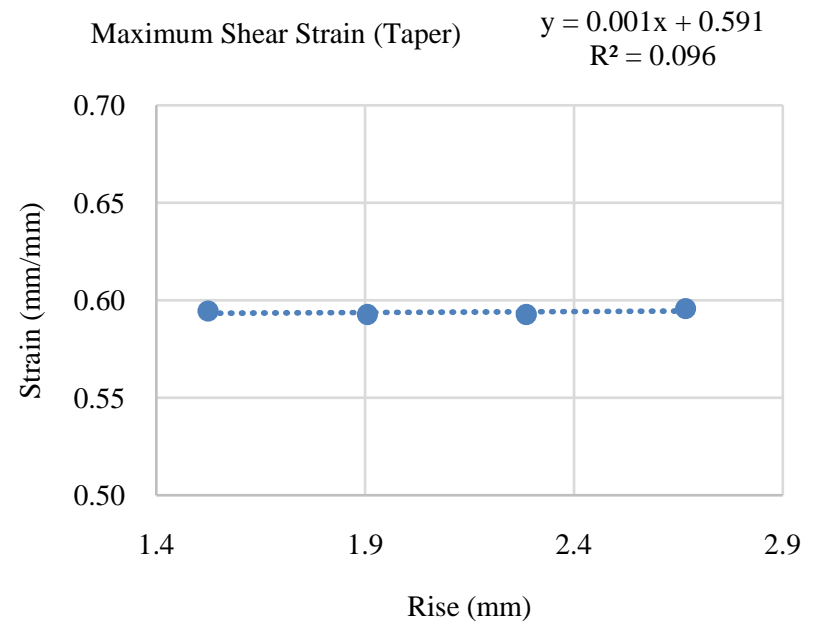

(a)

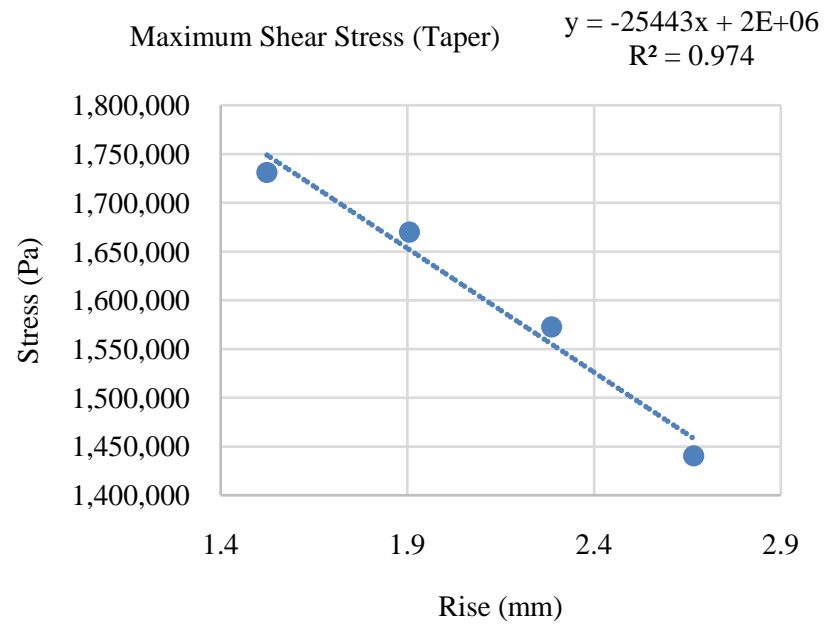

(b)

Figure 10. Device taper-regression analysis. (a) Strain results; (b) Stress results. 
Table 5. Device taper-design iterations and stress values.

\begin{tabular}{|c|c|c|c|c|}
\hline Model & $\begin{array}{l}\text { Taper } \\
(\mathrm{mm})\end{array}$ & Image & $\begin{array}{c}\text { Max Shear Strain } \\
(\mathrm{mm} / \mathrm{mm})\end{array}$ & $\begin{array}{c}\text { Max Shear Stress } \\
(\mathrm{Pa})\end{array}$ \\
\hline Cubed & $\begin{array}{l}1.524 \text { rise } \\
3.048 \text { run }\end{array}$ & & 0.59459 & $1,731,300$ \\
\hline Baseline & $\begin{array}{l}1.905 \text { rise } \\
3.810 \text { run }\end{array}$ & & 0.59267 & $1,669,900$ \\
\hline Slanted & $\begin{array}{l}2.286 \text { rise } \\
4.572 \text { run }\end{array}$ & & 0.59269 & $1,572,600$ \\
\hline Domed & $\begin{array}{l}2.667 \text { rise } \\
5.334 \text { run }\end{array}$ & & 0.59582 & $1,440,600$ \\
\hline
\end{tabular}

Table 6. Device taper-design iteration results.

\begin{tabular}{|c|c|c|c|c|c|}
\hline \multicolumn{6}{|c|}{ Height } \\
\hline Dimension (mm) & $\begin{array}{l}\text { Dimension } \\
\text { \%Change }\end{array}$ & $\begin{array}{c}\text { Strain } \\
(\mathrm{mm} / \mathrm{mm})\end{array}$ & $\begin{array}{c}\text { Strain } \\
\text { \%Change }\end{array}$ & $\begin{array}{l}\text { Stress } \\
(\mathrm{Pa})\end{array}$ & $\begin{array}{c}\text { Stress } \\
\text { \%Change }\end{array}$ \\
\hline 3.81 & $80 \%$ & 0.36813 & $52 \%$ & $1,746,867$ & $59 \%$ \\
\hline 5.08 & $90 \%$ & 0.53640 & $76 \%$ & $2,359,768$ & $79 \%$ \\
\hline 6.35 & $100 \%$ & 0.70468 & $100 \%$ & $2,972,669$ & $100 \%$ \\
\hline 7.62 & $110 \%$ & 0.87295 & $124 \%$ & $3,585,569$ & $121 \%$ \\
\hline \multicolumn{6}{|c|}{ Size } \\
\hline Dimension (mm) & $\begin{array}{l}\text { Dimension } \\
\text { \%Change }\end{array}$ & $\begin{array}{c}\text { Strain } \\
(\mathrm{mm} / \mathrm{mm})\end{array}$ & $\begin{array}{c}\text { Strain } \\
\text { \%Change }\end{array}$ & $\begin{array}{l}\text { Stress } \\
(\mathrm{Pa})\end{array}$ & $\begin{array}{c}\text { Stress } \\
\text { \%Change }\end{array}$ \\
\hline 15.24 & $60 \%$ & 0.352012 & $96 \%$ & $1,352,410$ & $85 \%$ \\
\hline 20.32 & $80 \%$ & 0.358616 & $98 \%$ & $1,469,880$ & $93 \%$ \\
\hline 25.40 & $100 \%$ & 0.365220 & $100 \%$ & $1,587,350$ & $100 \%$ \\
\hline 30.48 & $120 \%$ & 0.371824 & $102 \%$ & $1,704,820$ & $107 \%$ \\
\hline \multicolumn{6}{|c|}{ Taper } \\
\hline Dimension (mm) & $\begin{array}{l}\text { Dimension } \\
\text { \%Change }\end{array}$ & $\begin{array}{c}\text { Strain } \\
(\mathrm{mm} / \mathrm{mm})\end{array}$ & $\begin{array}{c}\text { Strain } \\
\text { \%Change }\end{array}$ & $\begin{array}{l}\text { Stress } \\
(\mathrm{Pa})\end{array}$ & $\begin{array}{c}\text { Stress } \\
\text { \%Change }\end{array}$ \\
\hline 2.667 & $60 \%$ & 0.594567 & $100 \%$ & $1,321,419$ & $87 \%$ \\
\hline 2.286 & $80 \%$ & 0.594186 & $100 \%$ & $1,418,359$ & $94 \%$ \\
\hline 1.905 & $100 \%$ & 0.593805 & $100 \%$ & $1,515,299$ & $100 \%$ \\
\hline 1.524 & $120 \%$ & 0.593424 & $100 \%$ & $1,612,240$ & $106 \%$ \\
\hline
\end{tabular}


the size of the taper and resulting stress, with an $\mathrm{R}^{2}$ value of 0.97 . Thus, increasing the rise and corresponding run of the taper by $1 \mathrm{~mm}$ will decrease the resultant stress by $2.5 \mathrm{e}^{5} \mathrm{~Pa}$.

\subsection{Summary of Results}

The results allow an identification of an optimal design of a body-adhered medical device. The device should have a square planform area with a thin height, small footprint, and large taper profile. Table 6 presents the data from each simulation compared to the baseline model. The resultant stress and strain of these models is likewise compared to the baseline stress and strain. By comparing the data in this way, it can be seen which design characteristic (height, size, or taper) had the largest impact on the resultant stress and strain.

A $10 \%$ reduction in device height resulted in a $21 \%$ reduction in stress and $24 \%$ reduction in strain. A $20 \%$ reduction in device size caused a $7 \%$ reduction in stress and $2 \%$ reduction in strain. A $20 \%$ increase in device taper size resulted in a negligible reduction in stress and a $6 \%$ reduction in strain.

\section{CONCLUDING REMARKS}

This study allows quantification of the relationships between a long-term body-adhered medical device and its ability to remain on-body through use of an adhesive patch. The analysis used a representative model of the system and an explicit dynamic finite element analysis method to calculate the mechanical stress and strain in the system with particular focus on values of stress and strain at the adhesion interface. The design of the medical device was iteratively changed to investigate a suite of designs with four design categories that totaled nineteen simulations. The resulting stress and strain were compared across designs within each suite and across all suites.

To minimize stress and strain experienced by the medical device and at the adhesion layer, the results indicate that the design should resemble a square shape, be short in height, and small in size with a large taper. However, changes to the height of the device were six times more impactful than the size at reducing stress and eight times more impactful than tapering for reducing strain. Therefore, a thin medical device design should be selected, if possible. Regarding shape, the square experienced $17.5 \%$ less stress than the next best performing shape.

\section{CONFLICTS OF INTEREST}

The authors declare no conflicts of interest regarding the publication of this paper.

\section{REFERENCES}

1. Center for Devices and Radiological Health (2020) Use of International Standard ISO 10993-1, Biological Evaluation of Medical Devices-Part 1: Evaluation and Testing within a Risk Management Process. U.S. Food and Drug Administration, Silver Spring, 51-54.

https://www.fda.gov/regulatory-information/search-fda-guidance-documents/use-international-standard-iso-10 993-1-biological-evaluation-medical-devices-part-1-evaluation-and

2. Bansal, A. and Joshi, R. (2018) Portable Out-of-Hospital Electrocardiography: A Review of Current Technologies. Journal of Arrhythmia, 32, 129-138. https://doi.org/10.1002/joa3.12035

3. Center for Devices and Radiological Health (2017) What Is an Infusion Pump? https://www.fda.gov/medical-devices/infusion-pumps/what-infusion-pump

4. National Institute of Diabetes and Digestive and Kidney Disease (2017) Continuous Glucose Monitoring. https://www.niddk.nih.gov/health-information/diabetes/overview/managing-diabetes/continuous-glucose-moni toring

5. Barry, H. and Ginsberg, M.D. (2019) Patch Pumps for Insulin. Journal of Diabetes Science and Technology, 13, 


\section{7-33. https://doi.org/10.1177/1932296818786513}

6. Dexcom G6 Review (2018) Type Lovely. http://typelovely.blogspot.com/2018/06/dexcom-g6-review.html

7. Huang, C.-J., Chiu, H.-C., Lee, M.-H. and Wang, S.-Y. (2011) Prevalence and Incidence of Anxiety Disorders in Diabetic Patients: A National Population-Based Cohort Study. General Hospital Psychiatry, 33, 8-15. https://doi.org/10.1016/j.genhosppsych.2010.10.008

8. Vance, C., Lawson, D.R., Cosgrove, D., et al. (2019) The Engineer's Guide to Wearables: Lessons Learned from Design Mishaps.

https://multimedia.3m.com/mws/media/1778887O/the-engineers-guide-to-wearables-lessons-learned-from-des ign-mishaps.pdf

9. Tebrake, M.G. (2014) Selecting the Right Medical Adhesive Tape: Challenges Facing the Medical Device Designer.

https://multimedia.3m.com/mws/media/1128482O/3m-medical-materials-and-technologies-medical-oem-white -paper.pdf

10. Akkus, O., Oguz, A., Uzunlulu, M. and Kizilgul, M. (2012) Evolution of Skin and Subcutaneous Adipose Tissue Thickness for Optimal Insulin Injection. Journal of Diabetes and Metabolism, 3, 1-5.

11. Pawlaczyk, M., Lelonkiewicz, M. and Wieczorowski, M. (2013) Age-Dependent Biomechanical Properties of the Skin. Advances in Dermatology and Allergology, 30, 302-306. https://doi.org/10.5114/pdia.2013.38359

12. Li, C.H., Guan, G.Y., Reif, R., Huang, Z.H. and Wang, R.K. (2011) Determining Elastic Properties of Skin by Measuring Surface Waves from an Impulse Mechanical Stimulus Using Phase-Sensitive Optical Coherence Tomography. Journal of the Royal Society Interface, 9, 831-841. https://doi.org/10.1098/rsif.2011.0583

13. Martin, A.D., Daniel, M.Z., Drinkwater, D.T. and Clarys, J.P. (1994) Adipose Tissue Density, Estimated Adipose Lipid Fraction and Whole Body Adiposity in Male Cadavers. International Journal of Obesity and Related Metabolic Disorders, 18, 79-83. https://pubmed.ncbi.nlm.nih.gov/8148928

14. Godbey, K. (2016) Skin versus Stainless Steel Adhesion Testing for Medical Design. https://multimedia.3m.com/mws/media/876307O/skin-vs-stainless-steel-adhesion-testing.pdf

15. LeBoeuf, C. (2021) Ansys Explicit Dynamics Takes over When Implicit Isn't Enough. https:/www.ansys.com/content/dam/product/structures/ansys-explicit-dynamics-brochure-140.pdf

16. ASTM Standard D3654/D3654M, 06 (2019) Standard Test Methods for Shear Adhesion of Pressure-Sensitive Tapes.

17. Chandraa, S. and Bhartib, A.K. (2019) Speed Distribution Curves for Pedestrians during Walking and Crossing. Proceedings of the 2nd Conference of Transportation Research Group of India (2nd CTRG), Agra, 12-15 December 2013, 660-667. https://doi.org/10.1016/j.sbspro.2013.11.160

18. Jost, S. (2021) Linear Correlation: Introduction. https://condor.depaul.edu/sjost/it223/documents/correlation.htm 